\section{World Materials Summit addresses energy, sustainability, and water}

www.mrs.org/2011wms

$\mathbf{T}$ he 2011 World Materials Summit, held on October 9-12, 2011, at the L'Enfant Plaza Hotel in Washington, DC, provided a forum for top decision makers and energy experts from around the world to focus on the materials research needs for the growing energy economy. Organized jointly by the Materials Research Society (MRS), the European MRS (E-MRS), and the Chinese MRS (C-MRS), the goal of the Summit was to explore how the different regions of the world can work together on the critical issue of clean energy, including its relation to environmental sustainability and water. The participants considered the area of materials research as well as advocacy, economics, outreach, and education. The Summit was chaired by Gabriel Crean of the Commissariat à l'Energie Atomique (CEA) (Europe), David Ginley of the National Renewable Energy Laboratory (USA), Yafang Han of the Beijing Institute of Aeronautical Materials (China), and Alan Hurd of Los Alamos National Laboratory (USA).

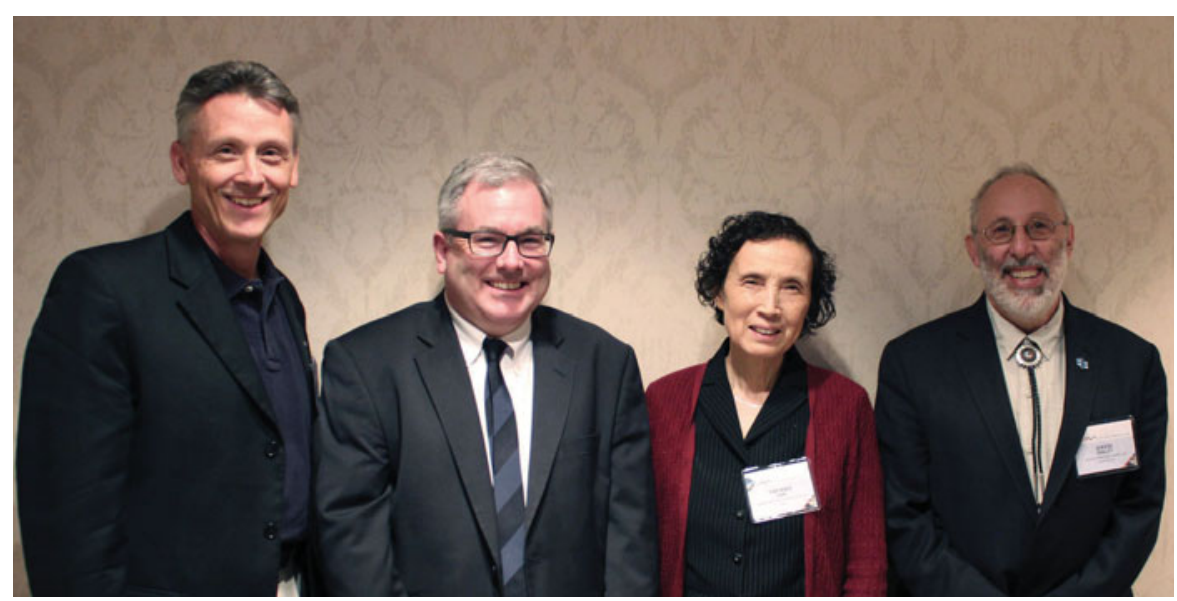

The 2011 World Materials Summit was chaired by (left to right): Alan Hurd (Los Alamos National Laboratory; Santa Fe Institute), Gabriel Crean (Commissariat à I'Energie Atomique), Yafang Han (Beijing Institute of Aeronautical Materials), and David Ginley (National Renewable Energy Laboratory). tions related to global access to clean energy and water in a sustainable way.

\section{Political landscape}

The Summit opened with keynote addresses by prominent representatives of the United States, Europe, China, and Mexico. They presented government policy and activity regarding materials for energy.

Steven Koonin, Undersecretary for Science at the U.S. Department of Energy, summarized DOE's inaugural Quadrennial Technology Review, which is intended to provide a systematic method to review the Department's research and development (R\&D) portfolio. The report defines six key strategies. Under the "transport" sector, DOE will devote its greatest effort to electrification of the vehicle fleet, including an increase in vehicle efficiency and deployment of alternative hydrocarbon fuels. In the "stationary" heat and power sector, the report finds that the Department should increase emphasis on efficiency and understanding the grid. DOE should also support R\&D toa day of overview presentations followed by a day of breakout sessions by topic. Participants of the Summit utilized these breakout discussions in order to assess and document global research and innovation needs, develop policies, and outline the future of advanced energy materials. The four-day effort culminated in a 2011 World Materials Summit Declaration delineating materials direc- ward increasing building and industrial efficiency and toward deployment of clean energy. The report was released last September and can be accessed at www.energy.gov/QTR.

Summit co-chair Gabriel Crean, Vice President of Technology for CEA, France, gave the audience a European perspective on energy and sustainability. The European Commission has established "Key Enabling Technologies (KETs)" on which to focus scientific research. In materials research, the six KETs are advanced materials, nanotechnology, micro- and nano-electronics, photonics, biotechnology, and advanced manufacturing. "KETs are essential to the development and manufacture of advanced products," Crean said. The final report by the high-level expert group on Key Enabling Technologies was released last 
June and is available on the European Commission website at ec.europa.eu.

Sergio Alcocer, Undersecretary for Energy Planning and Technology Development for Mexico, gave a broad overview of his country's energy sector. Under the Ministry of Energy there are two government-owned companiesPEMEX and CFE - three national energy research institutes, and four commissions. Alcocer reported some turmoil in Mexico over decisions to relax rules governing state-owned companies to increase investment capabilities. With this reform Mexico will be able to produce 3.3 million barrels of oil per day by 2024; without reform, this will be 2.2 million barrels per day. Alcocer also ad-

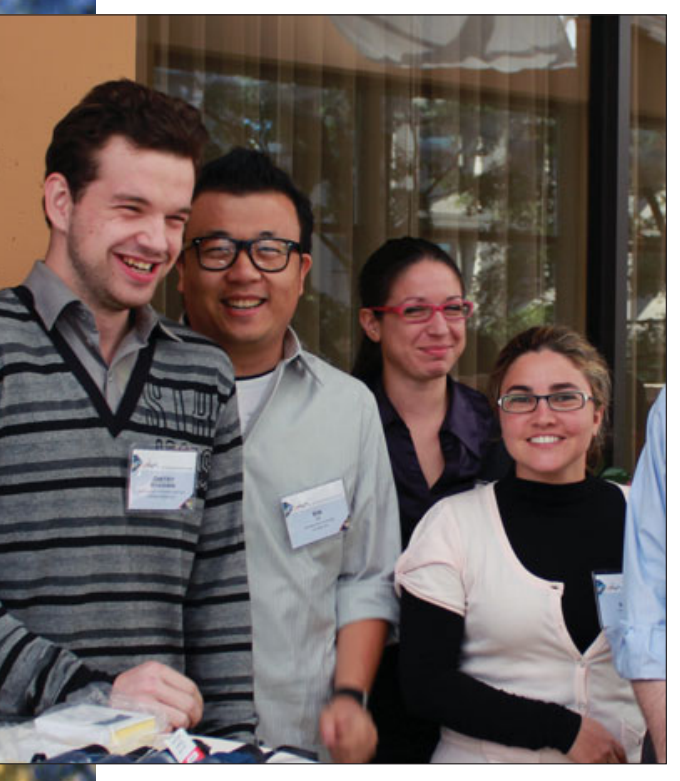

dressed researching nanotechnology in solar energy. He said Mexico's long-term strategy in energy focuses on energy security, efficiency, and sustainability. He further said that within Mexico's strategic partnership with the United States and Canada such topics become areas of opportunity for strengthening collaboration and establishing long-term, visionary, synergistic efforts in the region.

Dujin Wang of the Chinese Academy of Sciences (speaking on behalf of Xianhong Wang), made reference to the challenges in reducing the amount of $\mathrm{CO}_{2}$ emissions, then spoke not of China's governmental policy initiatives, but of the more technical aspect of $\mathrm{CO}_{2}$ as a feedstock for polymers. The most studied polymer in this field, according to Wang, is poly(propylene carbonate) (PPC). PPC is transparent, biodegradable, and a good oxygen barrier, but it has a low glass-transition temperature. Wang covered the evolution of this "ecopolymer" from a laboratory curiosity to industry activity in China.

\section{Smart grid}

Among the objectives of the Summit is to secure and develop a worldwide smart grid. In a plenary presentation, Paul Waide, director of European Energy Practice at Navigant Consulting, said that some of the main problems of today's grid are that electricity transfer is one way, transmission and distribution losses are as high as $15 \%$, and metering is not sophisticated, which leaves consumers confused about the costs of electricity. The solution will be a smart grid that uses digital technology to monitor and manage the generation and transmission of electricity from all sources (traditional and renewable) in order to meet the varying electrical demands of end users as efficiently as possible, according to Waide.

During a breakout session, a subgroup of the attendees determined that some of the regional smart-grid roadmaps may be deployable in the 2025-2050 time frame, but that worldwide development will need more time. The main materials challenges to establishing sustainable power grids reside in developing new energy storage materials, new methods of transmitting electricity efficiently over long distances, and control systems and smart materials for grid communications and control. The needs of longer term cable materials research include hightemperature superconductors, smart materials to mitigate natural risks, and heat- and flame-resistant polymers.

According to the group, many regional areas have roadmaps but broader international collaboration is needed to accelerate the developments in this field. Furthermore, the materials community needs to be made an integral partner in the discussion of smart-grid development as several technology issues, namely, storage and transmission, are fundamentally materials issues.
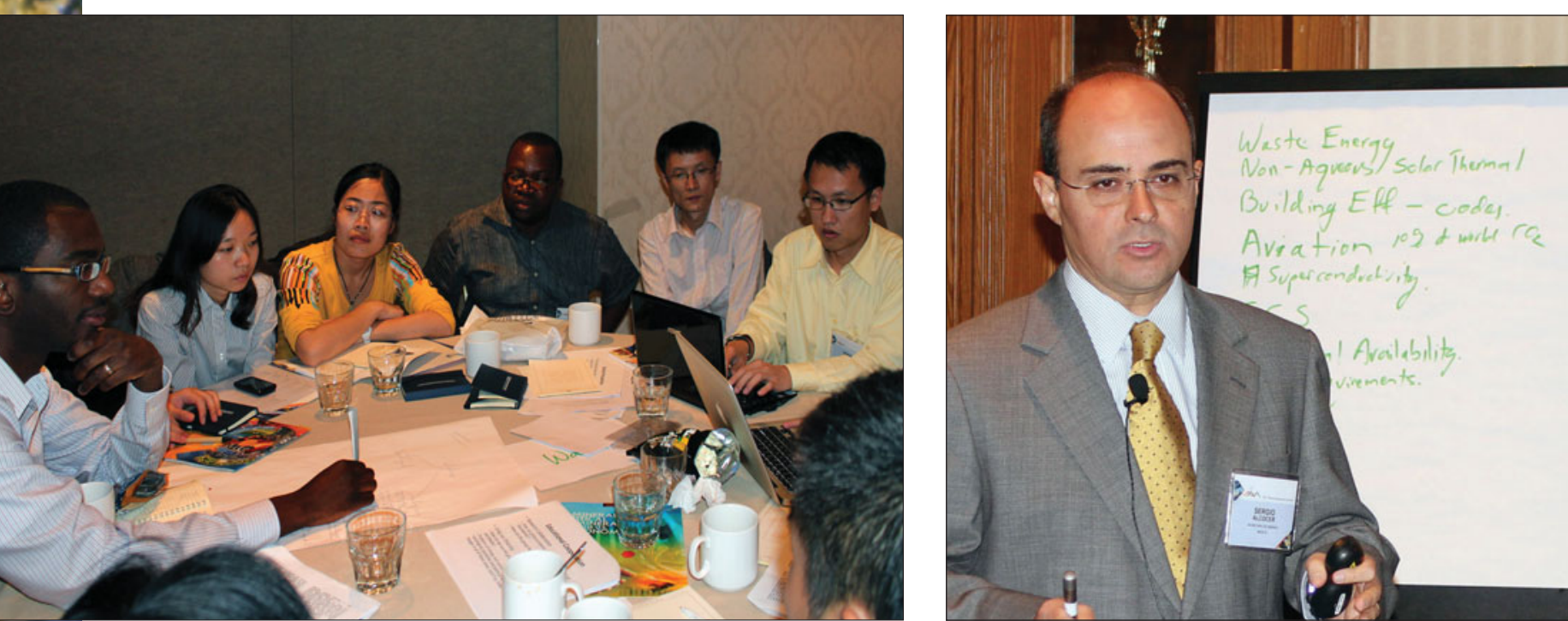


\section{Resource availability and life- cycle analysis}

All materials and processes have an environmental impact along their life cycles, said plenary speaker Duan Weng of Tsinghua University. However, it is not always easy to determine which material or option is better for the environment. For example, while the silicon solar cell is "green" during operation, it takes 3-5 years to reclaim the energy consumed during its manufacture. And while the electric vehicle is "green" during use, consideration must be given to the source of electricity and hydrogen. In China, about $80 \%$ of electricity comes from coal-fired power, said Weng. Life-cycle analysis can serve as a key component in materials selection and development, as various countries are becoming aware and determining policy to support it.

Another aspect of energy and sustainability is access to certain materials. "The materials community should be aware of risks associated with resource availability," said plenary speaker Randolph Kirchain of the Massachusetts Institute of Technology. When the cost of a resource skyrockets due to temporary scarcity, price changes can be temporary, but the effects on a manufacturing company can be permanent, he said.

A long-term goal, according to a breakout session on a topic related to sustainability, is having the raw materials required for energy technologies when they are needed, provided sustainably, at an affordable price. Analysis methods for resource production include consideration of the materials, the use of water and energy, and the effect on land and emission of greenhouse gases. The group in this session identified numerous opportunities for materials research, including the science for substitutions through materials discovery (e.g., alloys, nanomaterials, and components) in terms of composition, structure, and morphology. The group also cited opportunities in research on properties of and processes using recycled metals, efficient chemistries using $\mathrm{CO}_{2}$ as a raw material, and in developing more efficient and benign extraction and refinement processes. The

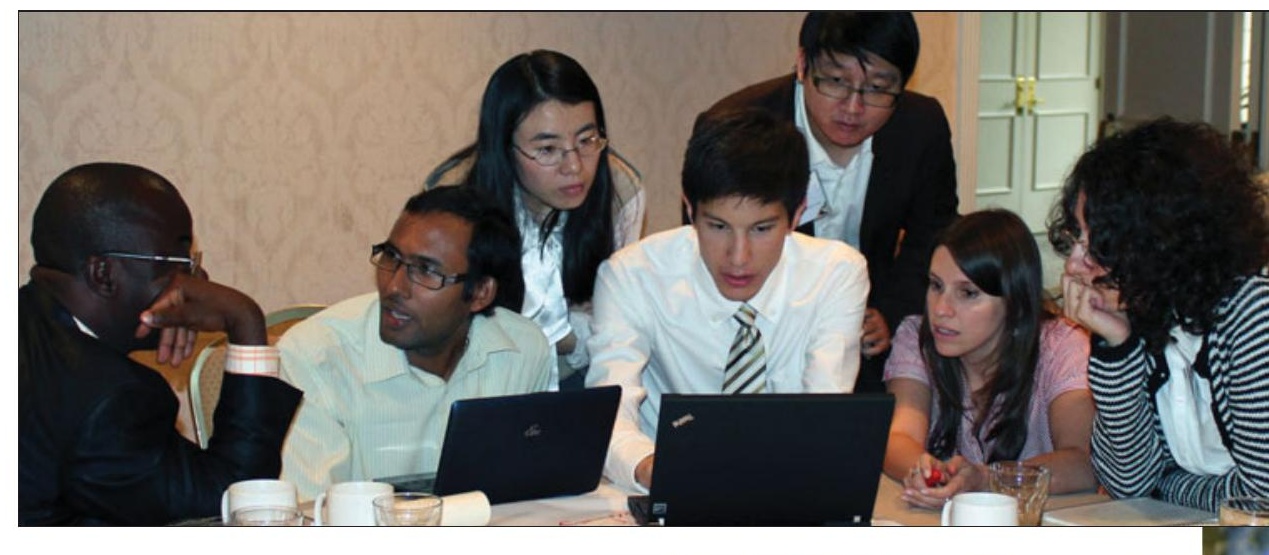

group also advocates international cooperation in areas such as coordination of research needs as well as programs and networks of information.

\section{Water use and purification}

Plenary speaker David Cahill of the University of Illinois, Urbana-Champaign illustrated the interdependent relationship of water and energy. Energy and power production require water in the areas of thermoelectric cooling, hydropower, production of fossil fuels and biofuels, and $\mathrm{CO}_{2}$ separation and sequestration, for example. Likewise, energy is needed for water treatment and distribution.

According to the breakout group that studied materials research opportunities for water, current trends in water purification and wastewater treatment include increased use of membrane separations and increased use of advanced oxidation for disinfection and the destruction of low-level toxic contaminants. Among the key goals the group identified is the development of low-cost, robust clean water systems with minimal energy and chemical inputs that can be deployed worldwide.

Significant reduction in costs can be achieved by developing materials with multiple functions. For example, membranes with the ability to self-clean or membranes that can both separate and disinfect could transform membrane processes, the group said. "Molecular level understanding of membrane separations is currently lacking," reported the group. For example, they said, "There is no quantitative understanding of the connections between the molecular structure of the membrane and water permeabil-

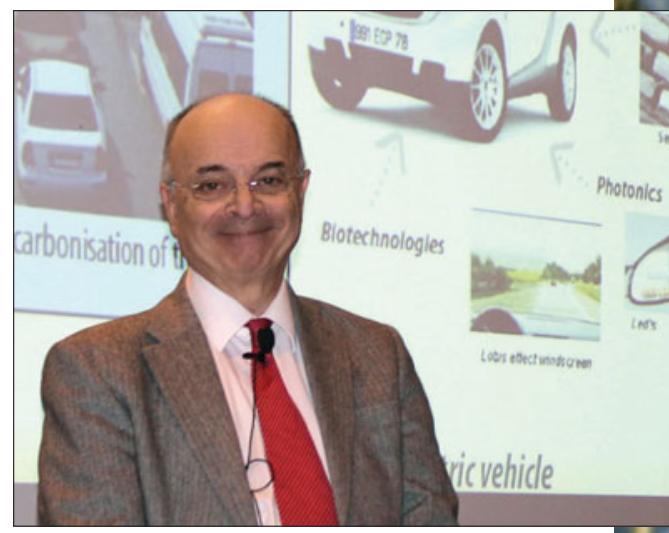

ity." Such gaps in knowledge stand in the way of designing new materials for specific applications.

\section{Energy sectors}

Plenary speakers and subgroup discussions also addressed various energy sectors. Jerry Gibbs of U.S. DOE Vehicle Technologies said that oil is predominantly a transportation energy problem. Reduction of oil consumption will depend on alternative fuels and electrification of vehicles, hybridization, efficiency increases in internal combustion engines, and lightweighting of vehicles. A 10\% mass reduction in an electric vehicle will result in a $10 \%$ increase in driving distance, Gibbs said.

In addressing renewable energy, George Crabtree of Argonne National Laboratory and the University of Illinois at Chicago said, "Complex, high-tech materials and chemistry are both the driver and the bottleneck for raising the performance and lowering the cost of renewable energy." He said that with traditional energy sources, the most important "material" is the fuel that is burned to turn heat into work. In the sustainable 


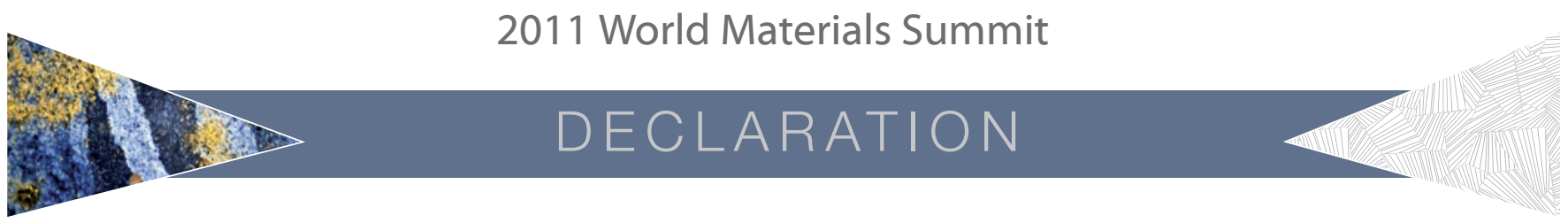

VISION: It is an inherent right of everyone on Earth to have access to clean energy and water in a sustainable way. Achieving this goal is a global endeavor that will require international coordination, cooperation and collaboration. Materials play a critical role in enabling viable solutions to these problems.

The 2011 World Materials Summit in Washington D.C., USA, identified opportunities and mechanisms to facilitate international cooperation focused on addressing materials solutions related to the critical needs of energy and water. The Summit was coupled to an International Student Congress providing key insights into opportunities for international networking, education and outreach.

\section{To achieve the vision, the Summit had the following key observations:}

- Mechanisms need to be developed for partnering, not only across international boundaries, but also across disciplines; solutions and their adoption will require partnering of materials scientists, sociologists, economists and policy experts as an integrated activity.

- Many fields need uniform international standards, many of which currently do not exist. Materials research societies should be conveners for these activities. They should also look at the possibility of developing metrics for sustainability.

- Energy efficiency, if broadly enhanced by materials science, represents one of the key opportunities for the materials research community to engage the global communities of users and developers in areas such as buildings. Recycling and recycling technologies are crucial opportunities for international collaboration.

- Future research and development must consider the abundance of materials and their accessibility. Green processing must be considered for new materials. Information resources, such as a Google-like prospector, are needed to assess resource availability. Developments should be cast in the context of potential global impact.

- Water is a critical resource for many technologies and is critical for the quality of life. International collaboration can enable the application materials science and engineering directly to the purification and processing of water worldwide.

- Sustained international cooperation and funding must be encouraged through government policies to move technologies to deployment. Mechanisms need to be put in place that facilitate collaboration throughout this process.

- Public outreach, a role of growing importance for the materials community, should be facilitated through international collaboration. The materials science community must develop tools and educational materials to foster public understanding.

- All forms of energy generation must be considered, without bias, in the context of societal impact, true risks, costs and sustainability.

- Scientists have a clear obligation to be advocates as a personal responsibility.

\section{Student Congress General Recommendations}

\section{ENERGY STATEMENT}

Provide unbiased reporting and analysis of energy technologies based on standardized sustainability metrics such as: greenhouse gas (GHG) emissions (actual, potential reductions), lifecycle analysis, risk assessment and reduction, region-specific assessments of potential technologies.

\section{MARKET AND ECONOMICS}

Address global imbalances in innovation and manufacturing through targeted funding to translate basic science into products, encouraging economic education, and initiating goal-based prizes for breakthrough materials.

\section{EDUCATION STATEMENT}

Support and maintain an online Global Resource Center for Sustainability (GRCS) that will provide educational lectures and demonstrations.

\section{OUTREACH STATEMENT}

Empower students to advocate for energy and sustainability to reach both policy makers and the general public in ways which are relevant and clear.

\section{WATER STATEMENT}

Develop appropriate technologies, educational awareness, and policies to encourage efficient water purification, management and access for a growing world population.

Expert and Student Congress panel reports available at www.mrs.org/2011wms. 